\title{
Cultura da visualidade e estratégias de (in)visibilidade ${ }^{1}$
}

\author{
Rose de Melo Rocha ${ }^{2}$ \\ ESPM/SP e PUCSP \\ rrocha@espm.br
}

\begin{abstract}
Resumo: Explorando uma ambigüidade constitutiva do termo "imagem" o artigo discute alguns de seus modos de existência na contemporaneidade, considerando as dinâmicas de reprodutibilidade, a lógica própria aos aparelhos de enunciação visual e as relações estabelecidas com mediações tecnológicas. Ao considerar a penetração das imagens no cotidiano e a transformação do próprio imaginário em imagem tangível, problematiza o conceito "cultura da visualidade", postulando ser necessário, para tal, promover-se a discriminação entre visual e visível ou, dito em outras palavras, entre visualidade e visibilidade.
\end{abstract}

Palavras-Chave: Imagem. Visualidade. Visibilidade.

Abstract: Exploring a constituent ambiguity of the term "image" the article argues some of its contemporary moods, considering the dynamic of reproducibility, the logic of visual apparatus and the relations established with technological mediations. Considering the penetration of the images in every-day-life and the transformation of imaginary in tangible image, put in question the concept of "culture of visuality", claiming to be necessary, for such, to discriminate visuality and visibility.

Keywords: Image. Visuality. Visibility.

\footnotetext{
${ }^{1}$ Apresentado no Grupo de Trabalho "Comunicação e Cultura" do XV Encontro da Compós (Unesp, Bauru, SP, junho de 2006).

2 Professora e pesquisadora do Mestrado em Comunicação e Práticas de Consumo da ESPM/SP e da PUCSP.
} 
Résumé: Explorant une ambiguïté constitutive du terme "image » l'article discute certains de ses modes contemporains, vu le dynamique de la reproductibilité, de la logique de l'appareil visuel et des relations établies avec des médiations technologiques. Vu la pénétration des images dans la vie quotidienne et la transformation d'imaginaire dans l'image réelle, mise en question le concept de "culture du visualité», prétendant être nécessaire, pour tels, distinguer le visualité et la visibilité.

Mots- clés: Image. Visuality. Visibilité.

Resumen: Explorando una ambigüedad constitutiva del término "imagen" el artículo discute algunas de sus disposiciones contemporáneas, en vista del dinámico de la reproducibilidad, de la lógica del aparato visual y de las relaciones establecidas con mediaciones tecnológicas. En vista de la penetración de las imágenes en la vida cotidiana y de la transformación de lo imaginario en imagen tangible, cuestiona el concepto de "cultura del visualidad", demandando ser necesario, para tales, discriminar visualidad y visibilidad.

Palabras-clave: Imagen. Visualidad. Visibilidad.

\section{Sobre modos de existência das imagens}

Algumas palavras têm por destino uma existência marcada por intrigante ambigüidade: embora densamente imersas no dia-a-dia e em nosso cotidiano discursivo, possuem uma dimensão etérea, dispersiva, fluída. É o que acontece com a palavra “imagem". Falamos, produzimos, consumimos e vivemos cercados por imagens. Imaginamos imagens. Criamos imagens. Até mesmo transformamos imagens imaginadas em concretas representações. E vice-versa. Somos capazes de sonhar com nossa própria imagem. Algumas imagens, por seu turno, são pura simulação. $O$ trânsito é intenso e os contrabandos de significação ininterruptos. 
Damos bom dia ou abominamos nossos espelhos. Às vezes duvidamos: sou eu mesmo ali, sou eu mesmo esta imagem? Outras blasfemamos: este espelho é cruel! Sou muito melhor do que esta imagem que avisto! Em algumas, é a eles que perguntamos: espelho, espelho meu, há no mundo alguém mais perfeito do que eu?

Edgar Morin (1997), em uma belíssima análise do encanto que cerca as imagens, postula que nada nos é mais sedutor do que a transformação do banal e do comezinho em registro imagético. Um duplo sentido cerca a "impressão de realidade" desta forma obtida, seja na fotografia, no cinema e, mais recentemente, na televisão e nas mídias digitais, embora estas últimas não tenham sido abordadas pelo autor. Morin, explorando a transformação do já visto em imagem - em espetáculo de imagens -, destaca do processo a experiência da fotogenia, esta "qualidade que reside, não na vida, mas na imagem da vida" (MORIN, 1997, p. 33).

Não por acaso, desenvolvemos relações da mais densa afetividade com nossos aparelhos de enunciação imagética: alguns preferem cumprimentar suas tevês, outros escolhem se emocionar com imagens capturadas por câmeras digitais. Nada surpreendente se, retomando Morin (2000), notarmos que neste plano da produção imagética somos transportados para um momento mágico, no qual a posse da representação equivaleria por contigüidade - à posse do representado.

Como apontado por Tom Sherman (1997), no delicioso artigo "Machines R Us...", cercamo-nos de equipamentos eletrônicos como bebês desesperadamente carentes, ávidos pela ampliação de nossa zona de conforto. Bebês dominadores e antropomórficos, diga-se de passagem, que carregam seus objetos tecnológicos como madames conduzem seus perfumados "lulus".

Mais fiéis do que cães, mais humanizadas que qualquer humano, tão amáveis quanto o mais prestimoso companheiro, mais reais que o mais fascinante "amigo imaginário", mais disponíveis que qualquer analista, assim seriam as máquinas, aquelas mesmas que, ao chamarmos de nossas, também agregam valor àquilo que chamamos de nós mesmos. 
Para Sherman, a relação de confiabilidade que se estabelece com o universo maquínico permite uma sugestiva redefinição da dicotomia público/privado. Naquela que autores contemporâneos vêm definindo como uma cultura da conectividade,

[d]ependemos das máquinas para olhar para fora e (...) para olhar para dentro. Então, para ficar em segurança, vamos nos certificar de que estamos off-line quando olhamos para dentro, on-line quando estamos olhando para fora. Vamos tentar ter certeza de que ninguém pode olhar para dentro quando estamos olhando para fora. (SHERMAN, 1997, p.71).

Em tal contexto, não é de se estranhar o fascínio experimentado ao nos tornarmos espectadores de imagens geradas através do registro obtido por câmeras ocultas. O inelutável sucesso dos flagrantes exibidos em programas televisivos apenas confirma e torna exponencial tal encanto. É também digno de nota o prazer com que proprietários de telefones celulares portadores de câmera fotográfica registram, a seu bel prazer e de modo "despistado", pessoas que as cercam, sejam estas suas amigas ou mesmo absolutamente desconhecidas. Vivendo da perversão sugerida por esta limiaridade, encontramos igualmente os paparazzi, sequiosos por transformar em imagem pública (on-line) a intimidade off-line de celebridades.

São máquinas que nos acompanham, são máquinas que nos protegem - de nós e dos outros -, são máquinas que nos colocam em relação - conosco e com os outros, consentida ou compulsoriamente - e, o que agora nos interessa, são máquinas que nos fazem ver, que nos fazem ser vistos e que nos permitem vermos-nos sendo vistos. "O estranho nisso tudo" - provoca Sherman - "é que nos tornamos tão dependentes de nossas máquinas para nos ajudar a ver e compreender o mundo, que dependemos de nossas máquinas para nos ajudar a ver a nós mesmos" (SHERMAN, 1997, p.71). Mas, afinal, quem observa quem?

Porteiros divertem-se com sua contemporânea ocupação de guardiões de imagens privadas. Assaltantes de condomínios de luxo não se esquecem de levar consigo as mais determinantes provas do crime: as fitas do circuito interno de televigilância. Alguns aceitam o convite e sorriem quando estão sendo filmados. Outros adoram fazer gestos obscenos 
para domésticos panópticos. Alguns olham para todos os lados. Outros desviam os olhos. Alguns preferem não olhar. Há aqueles que nada conseguem enxergar.

Todos têm na ponta da língua a óbvia constatação: imagens visuais assumiram um lugar determinante nas sociedades contemporâneas. Estamos inexoravelmente cercados por imagens visuais tecnicamente mediadas. Vivemos com o mundo na ponta do olho. O mundo, por sua vez, só nos sabe se nos puder ver. Para que nos veja transformamo-nos, às vezes a contragosto, em imagens dotadas de visualidade. Estranha mutação. Inversão radical de quaisquer iconoclastia só se ganha materialidade visual abdicando-se de densidade corpórea. Dispensamos o espírito do tempo para mais intensamente mergulhar no espírito do olhar.

Segundo Baitello Junior (2005), em seus estudos sobre a iconofagia, são agora as imagens que buscam pelos olhos humanos. Enquanto as consumimos, elas nos consomem:

Alimentar-se de imagens significa alimentar imagens, conferindo-lhes substância, emprestando-lhes os corpos. Significa entrar dentro delas e trasnformar-se em personagem (recorde-se aqui a origem da palavra "persona" como "máscara de teatro"). Ao contrário de uma apropriação, trata-se aqui de uma expropriação de si mesmo. (BAITELLO JUNIOR, 2005, p. 97).

A despeito de tão intensa proximidade, a despeito da permissividade que nos lança a este processo de consumação, poucos são capazes de nomear com clareza o que vem a ser a imagem; raríssimos aqueles que as conseguem precisamente definir. De onde parte esta indefinição? Por que cada vez mais foram se agregando a este conceito adjetivações e qualificações?

Se o grande impasse vivido em uma cultura da visualidade é o de conseguir encontrar os olhos para ver, será igualmente justo diagnosticar na crescente estetização da cultura um dos mais nodais focos de onde se abalam os pilares conviviais de sociedades fundadas na negociação entre cidadãos autóctones. A crise ética não é estranha à cenarização compulsória do social.

$\mathrm{Na}$ abordagem de Bauman (2004), a liquefação dos vínculos potencializada pelo advento da proximidade virtual - e, acrescentaríamos, pela profusão visual - , se não 
significa a supressão do contato, ocasiona o estabelecimento de contratos de relacionamento essencialmente fluídos. As conexões são muitas, mas também muitíssimo breves. O rol de contatos é enorme, mas por vezes parece difícil perceber estes outros com os quais nos conectamos em sua materialidade fenomêmica.

No universo da comutação a existência pulveriza-se em bits e a corporalidade fractaliza-se em imagem. O olhar que possibilita o encontro é o mesmo que reafirma a distância entre os corpos e a efemeridade da comunhão. E seguimos nos encontrando: aos solavancos, em trânsito, submersos no transe de uma visualidade excessiva, nesta erótica das miradas que tende a dispensar a erotização do face-a-face.

Não há justa medida possível se aceitarmos que todas as medidas são possíveis. Se tudo é cenário, o verdadeiro jogo é aquele que se dá nos bastidores e, astutamente, a indústria midiática, seja ela voltada ao entretenimento ou à informação, esforça-se para transformar os bastidores em espetáculo visualmente visível, ao modo de uma neutralização da real percepção do protagonismo que ali possa realizar-se.

Assim, em uma potente força de homogeneização, amalgamadas pela mesma lógica do espetáculo, tornam-se visíveis negociatas políticas, falcatruas econômicas, crises conjugais de estrelas televisivas. E o que é grave, ao pensarmos no impacto de tal ação, refere-se exatamente à indiferenciação aí gerada, ao convite à indiscriminação da natureza e dos diversos alcances daquilo que está sendo visibilizado.

Aprofundando tal possibilidade reflexiva, Baitello Junior (2005) sugere que

A cultura das imagens (e a transformação de toda a natureza tridimensional em planos e superfícies imagéticas) abre as portas para uma crise de visibilidade, dificultando aqui não apenas a percepção das facetas sombrias, mas até mesmo, por saturação, aquelas regiões iluminadas. Assim, como toda visibilidade carrega consigo a invisibilidade correspondente, também a inflação e a exacerbação das imagens agrega um desvalor à própria imagem, enfraquecendo sua força apelativa e tornando os olhares cada vez mais indiferentes, progressivamente cegos, pela incapacidade da visão crepuscular e pela univocidade saturadora das imagens iluminadas e iluminadoras. (BAITELLO JUNIOR, 2005, p.85) 
Mario Perniola (2000) detecta uma "socialização do imaginário" própria das sociedades midiáticas3. Historicizando o conceito de simulacro, imagem sem protótipo e sem identidade, "construção artificiosa que não possui original e que é incapaz de ser (...) ela mesma um original", Perniola afirma que ele "encontra as condições para uma plena realização nos meios de comunicação de massa contemporâneos" (PERNIOLA, 2000, p. 140). Segundo o filósofo,

Os meios de comunicação de massa, até o momento, têm em geral negado o seu caráter de simulacro. Ao considerar a si próprios como "espelho da realidade" ou do futuro diante de um público ainda profundamente impregnado de nostalgias metafísicas, chegaram às aberrações hiper-realistas e hiperfuturistas. ${ }^{4}$ Mas o seu valor não consiste na satisfação de pretensões metafísicas; ao contrário, ele implica precisamente o abandono de tais pretensões. Os meios de comunicação não podem ser a representação da realidade ou do futuro, porque são, antes de tudo, condições da experiência social presente e futura.(PERNIOLA, 2000, p.140)

\section{Visualidade e visibilidade}

Tomando por motivadores estes panoramas imagéticos, torna-se possível problematizar o corrente conceito de "sociedade da visualidade", inúmeras vezes utilizado para se descrever a contemporaneidade desde um ponto de vista dos impactos sócioculturais de sua produção imagética.

Nossa primeira postulação é a de que, ao promover a visualidade, a produção excessiva, ininterrupta e indiscriminada de imagens dotadas de materialidade e/ou externalidade visual, nossas sociedades midiáticas engendram um paradoxo: quanto maior e mais extensiva a profusão de visualidades, menor e menos intensiva é a possibilidade de

\footnotetext{
${ }^{3}$ Podemos, ainda, analisar a mídia, e não só os meios massivos, dialogando com outro conceito, desta vez moriniano. É possível percebê-la em sua qualidade de "duplo", de imagem material dotada de qualidade mental.

${ }^{4}$ Associadas, pelo autor, ao clássico embate entre iconoclastia e iconofilia: "os iconófilos contemporâneos são os realistas e os hiper-realistas dos meios de comunicação; os iconoclastas são os hiperfuturistas da autenticidade e da verdade alternativa. Em ambos permanecem operantes, a seu malgrado, as premissas filosóficas de seus predecessores religiosos." (PERNIOLA, 2000, p. 130).
} 
visibilidade. O que muito se mostra pouco se dá a ver. A visualidade excessiva é uma estratégia de invisibilidade.

A pulsão escópica assim realizada - no imperativo de um exibicionismo compulsório - coaduna-se a um tácito impedimento. Exibir-se em profusão é parte de uma artimanha irônica e cínica: mostrar-se em excesso sem nunca se revelar. Falastrões imagéticos são hábeis simuladores de veracidade. Mas, em verdade, nada há neles de exatamente verdadeiro. Antes, o que ali fascina é o falso absoluto, o tudo artificial, o opulentamente construído.

Culturas da visualidade legitimam uma transimagética, uma imagerie que só se torna crível exatamente por ser simulada, sequer almejando algo similar à verossimilhança. Vejam, o real não foi esquadrinhado pelas aparências. Sequer nelas reside o lugar de onde se seduziria o olhar. O que nos encanta não é o cenário. Aguardamos, isto sim, a ocupação, em primeiro plano, da vívida encenação de uma "fastamagoria" de bastidores.

A visualidade comporta um movimento pendular. Em um pólo, as representações impossíveis; em outro, o que só se dizima ao se representar:

Lyotard [1994], de modo brilhante, relata em minúcias o alcance e a trágica destruição operada pelas políticas de esquecimento. E estas o são, essencialmente, políticas de imagens, imagens que desconstróem memórias e naufragam imaginários. Penso, complementarmente, que a desconstrução opera-se igualmente pela evocação, por estas esplendorosas e insistentes políticas de aparecimento levadas a cabo pela cultura das mídias.

Sou eu o que vejo no espelho, de manhã, ao, sonolenta, escovar os dentes? Sou o que escrevo, sou as imagens que de mim capturaram as câmeras do telejornal local, sou mais verdadeiramente eu no click da polaroid, no instantâneo abrigado na carteira de motorista, nos desapercebidos registros do circuito interno de tevê instalado no prédio em que moro? Onde estou, se estou em toda parte? Talvez somente as imagens conheçam minha verdade. E a guardam para si. (ROCHA, 2005)

Tendo por base as observações acima registradas, estar-se-ia, ao que parece, diante de variados contratos imagéticos. Procura-se ora por uma ordenação, ora é-se surpreendido 
por uma sensação de hiper-realismo, como se a visualidade se tornasse mais real do que o real, como se ele, perdendo em potência de vinculação, cedesse lugar à sensibilização das imagens.

Analisando especificamente a imagem televisual, Jean-Marc Vernier (1988) propõe classificá-la a partir de três ordens, cada qual com um específico contrato de visibilidade, "implicando certa forma de crença, de adesão, um julgamento daquilo que se mostra, visando um telespectador ideal e prevendo um modo específico de relação deste com as imagens". Na primeira ordem, da "imagem-profundidade", o contrato visa a credibilidade das imagens, conferindo-lhes um caráter tátil, na remissão ao que seria uma "infância da televisão", quando se tomavam as coisas como de fato seriam, na presunção de uma objetividade pura.

Na segunda ordem, da "imagem-superfície", o contrato é o do espetáculo, baseado na necessidade e na primazia da mise-en-scène. Progressivamente, escreve Vernier, são os fragmentos de imagem que se dão a ver, conduzindo-nos à terceira ordem, da "imagemfragmento". Nesta, o contrato de visibilidade é energético, pulsante, é pura sensação. "Para o telespectador o mundo não é mais do que uma colagem de imagens, combinatório de intensidades visuais".

O limite do olhar, na oscilação entre as três ordens, sendo que a última tende a engolfar as demais, conduz-nos a um estado de suspense ininterrupto: imaginamos ver o real, e o que vemos é sua encenação; pensamos desfrutar de um teatro, quando, na verdade, o que se vê é real; em outros casos, gostaríamos que o real fosse uma encenação. Movimento ambíguo que, colocando em relevo, em mobilização incessante e fracionada a capacidade perceptiva, não possibilita que se saiba ao certo o que de fato nos aguarda e, menos ainda, o que será capaz de nos chocar. Em uma situação de paroxismo, os contratos são forjados na intensidade: a intensidade visual importa mais do que a intenção de visibilidade.

De modo a desenvolver este argumento, gostaria de elencar alguns dos vetores que, segundo percebo, podem ser associados ao que aqui se entende por visibilidade. Creio que, ao falarmos em visível, pressupomos não apenas uma qualidade daquilo que se dá a 
ver, que se constrói enquanto materialidade sígnica e efetividade simbólica. Penso, complementarmente, que visibilidade refere-se a uma "visualidade portadora de legibilidade" e, igualmente, de um estatuto hierarquicamente estabelecido e socialmente acordado de credibilidade.

Visibilidade associa-se, portanto, a mecanismos sócio-culturais partilhados que conferem, a determinadas imagens visuais, a qualidade de partícipes de sistemas de crença e de leitura visual reconhecíveis e reconhecidos. O que é visível remete menos ao que se tornou imagem visual e mais àquela visualidade que, via jogo societal e estratégias comunicacionais, é reconhecida como dotada de valor de troca simbólico e de relevância comunicativa. Visibilidade, finalmente, apenas se realiza e se consuma no momento do consumo, da recepção, da codificação, da interpretação e da tradução. É, ainda, um recorte significante particular feito em um todo visual múltiplo e abrangente.

Recorrendo a elementos históricos oferecidos pelas teorias da visão e da representação encontramos, desde os momentos mais primordiais, a tensão entre visualidade e visibilidade. Como exposto por autores como Régis Debray (1993) e Edgar Morin (2000), a imagem visual, em sua origem arcaica, ergue-se na suposição da invisibilidade: as pinturas nas ossadas que antecediam o sepultamento, os templos tumulares egípcios, cujo acesso se vetava aos vivos.

Posteriormente, representar-se-iam os próprios mortos. A eles, e a eles apenas, era assegurado o direito à visibilidade - lembrem-nos aqui da etimologia da palavra: imago, em uma de suas acepções, diz respeito à máscara de cera que se fazia dos que já haviam abandonado a vida. Se retornarmos ainda mais além, chegando às chamadas pinturas rupestres, encontraremos a mesma lógica.

As grutas serviam de suporte não para o retrato, para o registro instantâneo do que era visto. Na verdade, o que se depreende das inscrições é uma tentativa de tornar visível o já vivido - o ato sexual, o eclipse solar - ou, em outros casos, de se exercitar em visibilidade o que, futuramente, tornar-se-ia visualidade tangível - o encontro com a fera desconhecida, o enfrentamento armado, a caçada. 
Nas sociedades da visualidade excessiva, passado e futuro parecem, em verdade, condenados à total invisibilidade. O que se dá a ver é uma intensidade visual absolutamente presentificada. Excesso rima aqui com anestésico. A cultura da visualidade, encantada pela força de externalização da produção imaginária acaba colocando em risco parte de seu magma de subjetivação e de memória.

Talvez fosse interessante considerarmos não apenas a existência de em um jogo entre o visível e o (in)visível mas, igualmente, discriminar a tênue linha que demarca a passagem da visualidade à visibilidade. Se a visualidade delimita uma experiência cultural, falar em visibilidade pressupõe uma estratégia essencialmente política. Pressupõe-se analisar como, nas culturas da visualidade, constroem-se e se agenciam políticas de (in) visibilidade.

Penso, no segundo caso, que estamos diante de dispositivos de poder que, de modo sutil e não menos efetivo, constroem, em presença, não o que o olho vê, mas, fundamentalmente, o que a visão reconhece como fato relevante. Pressupõe-se, pois, que a visibilidade, como fato de visão, ultrapassa e reconfigura a consciência objetiva do que é visto, ganhando corpo e referencialidade palpável exatamente um convite ao exercício, guiado, de uma consciência subjetiva.

Nestes termos, cabe esclarecer que visibilidade diz respeito tanto a um processo de educação do olhar - quanto a um progresso - no exercício da interpretação e na afirmação da subjetividade. Deve-se ainda proceder a algumas discriminações. Se se pensar em termos da comunicação produzida massivamente (a tevê aberta, como um de seus mais notórios paradigmas) -, encontramos uma estratégia de visibilidade sendo forjada, intencionalmente aplicada desde o modo de produção das imagens visuais até a lógica de sua veiculação.

Também a encontraremos nos específicos contratos de visibilidade tacitamente estabelecidos entre consumidores e os diferentes veículos, acordando-se o que é digno de visibilidade e, obviamente, o que se deve manter invisibilizado. A relação entre a eficácia comunicativa dos produtos midiáticos e a inserção em macro-processos de visibilidade, articulando modos de ver, direcionamentos do olhar, imagens visuais e textuais, oferecem 
poderosas senhas de acesso à aquisição de visibilidade sócio-cultural, cada vez mais perpassada pelos hábitos de consumo.

Ambas, compondo um incessante diálogo, fazem ressoar modelos ideais de comportamento, sugestões acerca de estilo de vida, parâmetros de apresentação corporal e, obviamente, um verdadeiro álbum imagético que se oferece como referencial para construções identitárias.

Se seguirmos o raciocínio proposto por Arthur Kroker e David Cook (1991), poder-se-ia aí identificar a operação de uma estratégia midiática de estetização de princípios mercadológicos. Segundo nossos autores, a mídia, enquanto aparato social abrangente, melhor coloniza a psicologia individual sendo um "determinador de estados de espírito" [mood setter]. À propagação de imagens coaduna-se, portanto, um gerenciamento sensorial e comportamental decisivo, compondo um guia sobre como sentir e como se sentir.

As imagens assim compartilhadas são formas seriais de "modos de ser", espectros a serem alegremente consumidos. Embora analisem especificamente a televisão, a interpretação de Kroker e Cook é pertinente para abranger o significado de diferentes cenas midiáticas. Na proposição dos pesquisadores, a tevê, e segundo sugerimos, a mídia, pode ser definida como expressão paroxística da forma-mercadoria, "vivendo finalmente (como Marx profetizou) como uma pura imagem-sistema, como uma imagem televisiva espectral" (KROKER e COOK, 1991, p.268). A reificação, nestes termos, é solapada pela linguagem da significação.

Mais do que excesso ou pura e simples obscenidade das imagens, trata-se, em resumo, da inserção original das imagens na malha cultural e nas interações sociais contemporâneas. O consumo de imagens/sensações e de imagens/estilos-de-vida consolida um verdadeiro mercado de imagens ${ }^{5}$.

\footnotetext{
${ }^{5}$ A comunicação midiática propriamente dita - de alcance maciço, mas não massivo - nos permite identificar estratégias de visibilidade mais sofisticadas. É caso de algumas experiências na internet e nas tevês fechadas, é o caso das revistas segmentadas, dos serviços e produtos customizados.
} 
Também pelas brechas se faz a visibilidade. Os ativistas de culture jamming $g^{6}$, citando apenas um exemplo, valem-se da visualidade excessiva para ali construir sua proposta de legibilidade. Como pequenos gênios destampam as garrafas de grandes marcas, revelando e dando visibilidade, invariavelmente, à mitologia negativa dos produtos e serviços anunciados ${ }^{7}$.

As flash mobs ${ }^{8}$, por sua vez, servem-se do fluxo urbano e das redes tecnológicas para dar visibilidade a sua assumida e divertida efemeridade. Nas ruas da cidade, grafiteiros também exercitam uma astuciosa ação de visibilidade. Alguns optam por contrapor-se à lógica do excesso, da poluição visual. Outros, ainda mais argutos, ocupam-se de uma guerrilha lingüística codificada e hermética. Escolhem representar o irrepresentável e transformam o silêncio em grito de palavra.

\footnotetext{
${ }^{6}$ Trata-se da "prática de parodiar peças publicitárias e usar os outdoors para alterar drasticamente suas mensagens" (Klein, 2002:308).

${ }^{7}$ No emblemático trabalho de Klein (2002), encontramos que "o termo (...) foi cunhado em 1984 pela banda de audiocolagem Negativland, de San Francisco. (...) Uma boa jam, em outras palavras, são raios X do subconsciente de uma campanha, revelando não um significado oposto, mas a verdade mais profunda oculta sob as camadas de eufemismos publicitários" (Klein, 2002: 309).

${ }^{8}$ Mobilizações instantâneas realizadas em centros urbanos de todo o mundo, valem-se, para sua convocação, do contato através de Internet e telefonia celular. Lembremos aqui que o mesmo recurso está sendo utilizado como meio de mobilização nos recentes conflitos envolvendo jovens filhos de migrantes ocorridos em Paris, obviamente que a serviço de uma ação de proposta e efeito diverso.
} 


\section{Referências bibliográficas:}

Baitello, Norval. A era da iconofagia. Ensaios de comunicação e cultura. São Paulo, Hacker, 2005.

Bauman, Zygmunt. Amor líquido. Sobre a fragilidade dos laços humanos. Rio de Janeiro, Jorge Zahar, 2004.

Debray, Régis. Vida e morte da imagem. Petrópolis, Vozes, 1993.

Klein, Naomi. Sem logo. A tirania das marcas em um planeta vendido. Rio de Janeiro, Record, 2002.

Kroker, Arthur e Cook, David. The postmodern scene. Excremental culture and hyper-aesthestics. Montréal, New World Perspectives, 1991.

Lyotard, Jean-François. Heidegger e os judeus. Petrópolis, Vozes, 1994.

Morin, Edgar. O paradigma perdido. Lisboa, Europa-América, 2000.

Morin, Edgar. O cinema ou o homem imaginário. Lisboa, Relógio D’Água, 1997.

Perniola, Mario. Pensando o ritual. Sexualidade, morte, mundo. São Paulo, Studio Nobel, 2000.

Rocha, Rosamaria Luiza (Rose) de Melo. "Imagens limiares e seus fabulosos fabuladores”. Paper apresentado no XIV Encontro Anual da Compôs. Niterói, UFF, 01 a 04 de junho de 2005.

Sherman, Tom. “Machines R Us...”. In: Domingues, Diana (org.). A arte no século XXI. A humanização das tecnologias. São Paulo, Unesp, 1997, pp. 70-78.

Vernier, Jean-Marc. "Trois ordres de l'image télévisuelle". Quaderni, $\mathrm{n}^{0}$ 4, primavera de 1988. Paris, CREDAP, Université Paris Dauphine, pp. 9-18 (tradução da autora). 